\title{
Review
}

\section{Spinal shock revisited: a four-phase model}

\author{
JF Ditunno*,1, JW Little ${ }^{2}$, A Tessler ${ }^{3}$ and AS Burns ${ }^{1}$ \\ ${ }^{1}$ Department of Rehabilitation Medicine, Thomas Jefferson University, Philadelphia, PA, USA; ${ }^{2}$ Department of \\ Rehabilitation Medicine, University of Washington, Seattle, WA, USA; ${ }^{3}$ Department of Neurobiology and Anatomy, \\ Drexel University College of Medicine, Philadelphia, PA, USA
}

\begin{abstract}
Spinal shock has been of interest to clinicians for over two centuries. Advances in our understanding of both the neurophysiology of the spinal cord and neuroplasticity following spinal cord injury have provided us with additional insight into the phenomena of spinal shock. In this review, we provide a historical background followed by a description of a novel fourphase model for understanding and describing spinal shock. Clinical implications of the model are discussed as well.
\end{abstract}

Spinal Cord (2004) 42, 383-395. doi:10.1038/sj.sc.3101603; Published online 23 March 2004

Keywords: spinal cord injuries; neuronal plasticity; abnormal reflexes

\section{Introduction}

Depressed spinal reflexes caudal to spinal cord injury (SCI), defined as spinal shock, have intrigued clinicians and researchers for more than two centuries. Despite this history, the etiology and significance of spinal shock remain controversial. In this review, we revisit spinal shock from a fresh perspective, extrapolating from the vast outpouring of basic neuroscience research, in an attempt to explain clinical observations of spinal shock. We begin with a historical background, postulate a novel four-phase model of spinal shock (see Table 1), and then conclude with a discussion of future research questions and possible treatments to improve clinical outcomes. By understanding spinal shock better, we can gain insight into the neuronal changes that occur distal to SCI and how to potentially improve outcomes by modulating the process.

\section{Historical perspective}

\section{The definition is controversial}

In 1750, Whytt first described the phenomenon of spinal shock as a loss of sensation accompanied by motor paralysis with gradual recovery of reflexes. ${ }^{1}$ He did not use the term shock nor was the anatomical basis for reflexes understood at the time. Hall ${ }^{2}$ later introduced the term 'shock' in 1841:

If, in a frog, spinal marrow (cord) be divided ... for a very short time no diastolic actions (reflexes) in

*Correspondence: JF Ditunno, Department of Rehabilitation Medicine, Thomas Jefferson University, 132 S. 10th Street, 375 Main Building, Philadelphia, PA 19107, USA the extremities (are present, then) the diastolic actions (reflexes) speedily return. This phenomenon is shock.

He also used the term 'reflex arc' to describe reflexes. ${ }^{2}$ Hall was therefore the first to use both the terms 'spinal shock' and 'reflex arc' and to link the two phenomena. ${ }^{3}$

Since Hall's description 150 years ago, the implications and physiologic basis of spinal shock have been a source of ongoing debate and discussion. Several recent editorial comments ${ }^{4,5}$ and articles ${ }^{6,7}$ have criticized the term as being a source of confusion. Atkinson and Atkinson ${ }^{6}$ point out that hypovolemic shock and spinal shock are frequently confused and this can lead to serious mismanagement ${ }^{4}$ as the former requires fluid replacement and the latter vasopressors. The physiologist Sherrington ${ }^{8}$ also recognized the potential for confusion in his description of 'shock' and distinguished between circulatory shock and spinal shock.

In some forms of the clinical condition, circulatory disturbances and inspissations of the blood play a part in 'shock,' but, as understood by the physiologist, 'shock' is primarily a nervous condition... I myself, mean by the term the whole of that depression or suppression of nervous reaction, which ensues forthwith upon a mechanical injury of some part of the nervous system, and is of temporary nature.

There continues to be a lack of consensus on the clinical symptomatology that defines the duration of spinal shock. Some clinicians ${ }^{9,10}$ interpret spinal shock 
Table 1 Phases of spinal shock

\begin{tabular}{llll}
\hline $\begin{array}{l}\text { Phase 1, (0-1 day) } \\
\text { areflexia/hyporeflexia }\end{array}$ & $\begin{array}{l}\text { Phase 2, (1-3 days), } \\
\text { initial reflex return }\end{array}$ & $\begin{array}{l}\text { Phase 3, (1-4 weeks), } \\
\text { initial hyper-reflexia }\end{array}$ & $\begin{array}{l}\text { Phase 4, (1-12 months), final } \\
\text { hyperreflexia }\end{array}$ \\
\hline $\begin{array}{l}\text { Loss of descending } \\
\text { facilitation }\end{array}$ & $\begin{array}{l}\text { Denervation } \\
\text { supersensitivity }\end{array}$ & $\begin{array}{l}\text { Axon-supported synapse } \\
\text { growth }\end{array}$ & $\begin{array}{l}\text { Soma-supported synapse } \\
\text { growth }\end{array}$ \\
\hline
\end{tabular}

as ending with the appearance of the bulbocavernosus reflex within the first few days of injury. Others ${ }^{11,12}$ state that it ends with the recovery of deep tendon reflexes (DTRs), which in complete human SCI may not reappear for several weeks. ${ }^{7}$ Still other clinicians define the resolution of spinal shock as the return of reflexive detrusor function months following injury. Sherrington ${ }^{1,8}$ felt that 'noci-ceptive' (polysynaptic) reflexes were depressed for a shorter duration than monosynaptic DTRs. Guttmann ${ }^{13}$ repeated Sherrington's observations that all reflexes are initially depressed, but added the qualification that some cutaneous (polysynaptic) reflexes are unaffected. Sherrington ${ }^{8}$ stated in his Croonian Lecture that the duration of spinal shock is a matter of definition:

How long the phenomena of shock may last at longest is a question on which very different views are held. Goltz... (believes)... shock may persist for months, even years. It is merely a matter of nomenclature. I...(believe that)... shock does not at longest persist for more than a few days.

If the duration of spinal shock is defined by the initial recovery of any reflex, then it probably lasts no longer than 20 min- 1 h. ${ }^{1,8}$ If, however, spinal shock is defined as an absence of DTRs, an interpretation that persists today, then its duration is several weeks. ${ }^{11,12}$

\section{Time course and pattern of reflex recovery}

Illis ${ }^{14}$ stated that without a description of reflex recovery the current definition of spinal shock as an absence of all reflexes was meaningless. Ko et $a l^{7}$ prospectively studied reflex recovery in 50 subjects admitted within $24 \mathrm{~h}$ following SCI. These authors refer to spinal shock as a state 'of altered appearance of cutaneous and deep tendon reflexes and the emergence and at times disappearance of pathological reflexes over days and weeks'. The study emphasizes the importance of the evolution of reflexes and the relationship of the delayed plantar response (DPR) to prognosis. Based on observations of injured soldiers during World War I, Guillain and Barre ${ }^{15}$ were the first to describe the DPR in humans. They stated that it develops within 1-6h following severing of the spinal cord.

The DPR requires an unusually strong stimulus applied by stroking with a blunt instrument upward from the heel toward the toes along the lateral sole of the foot continued medially across the volar aspects of the metatarsal heads (3rd, 4th and 5th digits). After the stimulus is applied, the onset of the plantar flexion response of the great toe and/or other toes is always delayed.

Sherrington did not mention this reflex in his most cited work, ${ }^{1}$ but described a response in monkeys that has many similarities. ${ }^{8}$

'for about 20 minutes after... severance, neither by mechanical, thermal, nor electrical excitation of the skin innervated from below the point of severance, can any reflex movement at all be elicited'.

'After the brief interval certain skin reflexes begin to appear; almost always earliest is the adductionflexion of the hallux, elicitable by stimuli applied to the $3 \mathrm{rd}$, 4th, or 5th digits (plantar surface or sides), or to the skin of the sole, especially on the fibular side'.

The DPR is generally the first reflex to appear and can often be observed in the emergency room. ${ }^{7}$ The persistence of the DPR beyond 7 days is associated with severe SCI and a poor prognosis for ambulation. Following the appearance of the DPR, reflexes tend to return in the following sequence: bulbocavernosus $(\mathrm{BC})$, cremasteric (CM), ankle jerk (AJ), Babinski sign, and knee jerk (KJ) (Table 2). ${ }^{7}$ The general pattern of recovery appears to be cutaneous (polysynaptic) reflexes before DTRs ${ }^{7}$ rather than the caudal to cranial recovery proposed by Guttmann. ${ }^{13}$

\section{A new paradigm of spinal shock}

Previous descriptions of spinal shock require clarification for two reasons: (1) not all reflexes are uniformly abolished in humans, since some reflexes are often only depressed and can be elicited, and (2) spinal shock does not resolve abruptly but rather in a series of phases extending over days to weeks to months. Illis ${ }^{14}$ suggests spinal shock cannot be adequately described unless it is divided into phases: 'the first phase of spinal shock (depression of reflexes)... withdrawal of impulses from descending tracts... (is not) acceptable unless it includes the second phase... return of reflexes in an altered form'. The resolution of spinal shock merges with the appearance of hyperactive spinal reflexes. Therefore, to understand spinal shock we must also understand the neuronal processes that mediate spinal hyper-reflexia. 
This review focuses on the spinal cord caudal to injury, specifically the spinal neurons isolated from descending excitatory and inhibitory input. Isolated neurons do not lose all synaptic inputs; they retain synaptic contacts from reflex afferents and interneurons and they may acquire new contacts from sprouting neurons. ${ }^{16,17}$ For simplicity, we focus our discussion of spinal shock on clinically complete SCI. The model consists of four evolving phases for which we provide clinical and physiological descriptions (Table 3). Through a better understanding of the underlying mechanisms of spinal shock, we may be able to offer novel interventions that facilitate recovery. ${ }^{14}$

\section{Phase I: areflexia/hyporeflexia (0-1 day)}

\section{Clinical description 0-1 day}

The first phase of spinal shock occurs from 0 to $24 \mathrm{~h}$ postinjury. Caudal to complete SCI, DTRs such as the AJ and the KJ are initially absent, and muscles are flaccid and paralyzed. During this period, cutaneous (polysynaptic) reflexes such as the $\mathrm{BC}$, the $\mathrm{AW}$, and the $\mathrm{CM}$ begin to recover. Thus, the absence of all reflexes is uncommonly observed during the initial $24 \mathrm{~h}$ if a careful neurological examination is performed. ${ }^{7}$ A pathologic reflex, the DPR, is usually the first reflex to return and can be observed within hours of injury. ${ }^{7}$ In most cases, it is transient and disappears within several weeks. The DPR requires an unusually strong stimulus, in contrast to the Babinski sign or normal plantar response, and is elicited by stroking a blunt instrument upward from the heel toward the toes along the lateral sole of the foot and then continuing medially across the volar aspect of the metatarsal heads. In response to the stimulus, the toes flex and relax in a delayed sequence. Ko et $a l^{7}$ found that the DPR occurred in $22 / 31$ cases during this period. ${ }^{7}$ It is at times robust with full excursion of the toes in flexion. In complete injuries, the $\mathrm{BC}$ can occur simultaneously (16/ 31) with the DPR, but it often lags behind and may not be evident for several days. The cremasteric reflex is seen in approximately $1 / 3$ of subjects $(6 / 20)$ in the initial phase.

Bradyarrhythmias, atrioventricular conduction block, and hypotension occur following cervical lesions due to impaired sympathetic innervation in the setting of preserved cranial nerve (vagus) mediated parasympathetic function. Stimulation of the bronchi by aggressive suctioning of secretions can result in bradyarrhythmias or conduction block. Although the exact duration from injury to resolution of autonomic abnormalities is not well documented, it is our experience that they persist through Phases 2 and 3.

\section{Physiology 0-1 day: spinal neuron hyperpolarization}

Spinal motor neurons and interneurons receive continuous background excitatory input from supraspinal axons, due in part to the waking state and vigilance. Voluntary movement is superimposed on this background excitation. Following SCI, background excitation is lost and spinal neurons become less excitable; this is likely the primary cause of reflex depression during spinal shock. A similar reflex depression can be created transiently by blocking spinal axon conduction via procaine injection into the thoracic cord or cooling, ${ }^{18}$ the hyperpolarized lumbar motor neurons and interneurons then respond less vigorously to segmental reflex inputs. Clinically, this is the hyporeflexia of spinal shock.

Supraspinal inputs mediating background excitation are multiple and likely include vestibulospinal and reticulospinal pathways among others. Hyporeflexia is observed with lesions below the mid-pons level; lesions above this level produce decerebrate rigidity. Serotonergic $(5-\mathrm{HT})$ neurons of the raphe nucleus and noradrenergic (NE) neurons from the locus coeruleus may contribute much of this basal excitatory input. ${ }^{19,20} 5-\mathrm{HT}$ and NE act on spinal motor neurons yielding plateau potentials, which may amplify excitatory inputs including reflex inputs. ${ }^{21-23}$ Plateau potentials originate on dendrites and amplify excitatory inputs up to six-fold, thus leading to sustained firing with minimal excitatory input. ${ }^{24}$ This effect may be due to prolonged activation of $\mathrm{Ca}^{2+}$ channels.

Other mechanisms may also contribute to spinal shock. Gamma-motor neurons regulating tension of muscle spindles may fire subliminally to maintain background excitability in muscle spindles; ${ }^{25,26}$ caudal

Table 2 Recovery of reflexes: four phases of spinal shock

\begin{tabular}{|c|c|c|c|c|}
\hline & $0-1$ day & 1-3 days & 1-4 weeks & $1-12$ months \\
\hline DPR & +++ & +++ & $+/ 0$ & $+/ 0$ \\
\hline $\mathrm{BC}$ reflex & $+/ 0$ & ++ & ++ & ++ \\
\hline AW reflex & $+/ 0$ & ++ & ++ & ++ \\
\hline CM reflex & $+/ 0$ & ++ & ++ & ++ \\
\hline Babinski sign & 0 & + & ++ & ++ \\
\hline Flexor withdrawal reflex & 0 & $+/ 0$ & ++ & +++ \\
\hline DTRs & 0 & $+/ 0$ & ++ & +++ \\
\hline Tibial H-reflex & 0 & ++ & + & +++ \\
\hline Extensor spasm & 0 & 0 & 0 & +++ \\
\hline Interlimb reflexes & 0 & 0 & 0 & +++ \\
\hline Reflex neurogenic bladder & 0 & 0 & 0 & +++ \\
\hline Autonomic hyper-reflexia & 0 & 0 & 0 & +++ \\
\hline
\end{tabular}


Table 3 Proposed mechanisms for the four phases of spinal shock

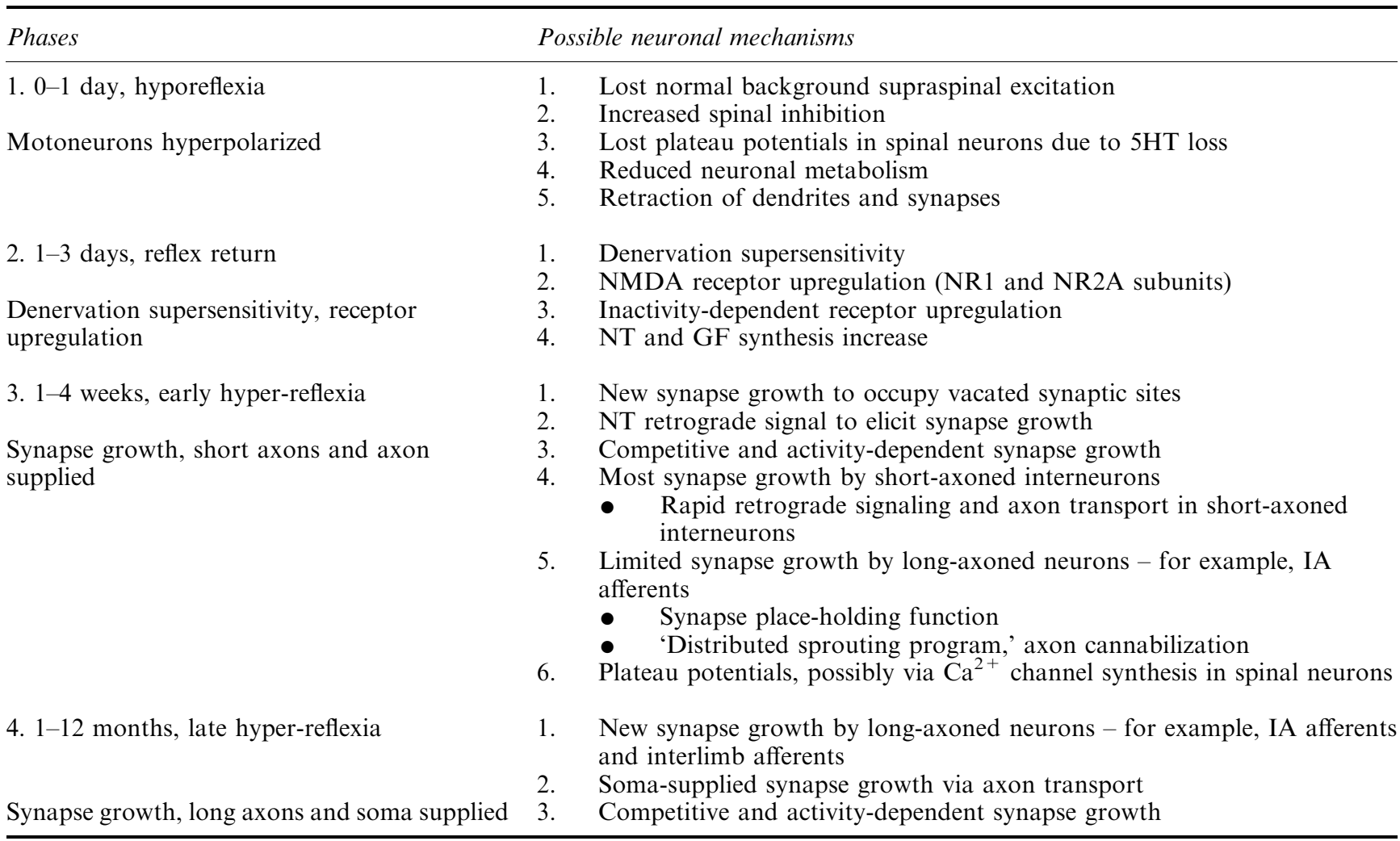

to SCI, gamma-motor neurons may lose tonic descending facilitation, resulting in reduced muscle spindle excitability and less segmental input to motor neurons by stretch reflex afferents. Depressed reflexes may also be due to increased spinal inhibition. ${ }^{27}$ Although many descending pathways are excitatory, some are inhibitory. Cord transection may reduce normal descending inhibition to spinal inhibitory pathways, which could then contribute to the depression of spinal reflexes. ${ }^{28}$ Later, metabolic or structural changes in spinal neurons could contribute to reflex depression. ${ }^{29,30}$ Dendrites of spinal cord neurons retract and many synapses degenerate within 1-3 days following SCI. ${ }^{31,32}$ Dendrite retraction and synapse loss in the isolated caudal cord likely reflects impaired release and uptake of neurotrophins and growth factors in hypoactive spinal neurons. ${ }^{31,32}$ The hyporeflexia of spinal shock, however, appears immediately after SCI. So, although metabolic and structural changes may contribute to initial hyporeflexia, these are likely not the primary cause.

\section{Phase 2: initial reflex return (1-3 days)}

\section{Clinical description 1-3 days}

The second phase of spinal shock lasts for 1-3 days postinjury. Cutaneous reflexes (BC, AW, and cremasteric) become stronger during this period. Typically,
DTRs are still absent, although the tibial H-reflex returns by about $24 \mathrm{~h},{ }^{33,34}$ perhaps because the H-reflex afferent volley is less dispersed than that of the AJ reflex. ${ }^{35}$ In elderly subjects with a complete injury, the DTRs and Babinski sign can occur during this phase. ${ }^{7}$ It has been postulated that pre-existing subclinical myelopathy might contribute to early reflex recovery in older individuals. ${ }^{7}$ In support of this, animal studies have shown faster recovery of DTRs in the setting of prior upper motor neuron lesions. ${ }^{36,37}$ Interestingly, Guttmann $^{38}$ stated that children also begin to recover DTRs as early as 3 days following injury, perhaps because descending supraspinal tracts in children are not fully developed compared to adults, thereby predisposing to relative spinal hyper-reflexia.

\section{Physiology 1-3 days: denervation supersensitivity/ receptor upregulation}

Denervation supersensitivity likely plays a role in initial reflex re-emergence. ${ }^{39-41}$ Such supersensitivity to neurotransmitters, that is, increased neuronal firing in response to neurotransmitter, is well known in denervated neurons of both the peripheral and central nervous systems (PNS and CNS). Denervation supersensitivity occurs in the spinal cord as well as in the brain. ${ }^{42-46}$ Proposed mechanisms of denervation supersensitivity include: (1) reduced excitatory neurotransmitter reuptake, (2) increased synthesis and insertion of 
receptors into postsynaptic membrane, ${ }^{47,48}$ (3) decreased removal and degradation of receptor, ${ }^{48}$ and (4) altered synthesis and composition of receptor subunits. ${ }^{48-50}$ All of these could occur quickly and be consistent with reflex change at 1-3 days. Upregulation in mRNA transcription and protein translation begins within hours and peaks in days. ${ }^{48}$ An increase in intracellular calcium associated with neuronal hypoactivity may be the trigger for an increase in transcription-translation of receptors, channels, and growth factors. ${ }^{51}$ This denervation supersensitivity in spinal neurons is likely, at least in part, a form of 'synaptic scaling', as described elsewhere in central neurons. ${ }^{48}$

Increased synthesis of excitatory NMDA glutamate receptors in motor neurons caudal to a SCI is suggested by increased concentration of mRNA for NMDA receptor subunits (both NR1 and NR2A). ${ }^{49,52}$ Increased mRNA transcription of NMDA receptor subunits develops by $24 \mathrm{~h}$ and persists at least a month caudal to a spinal injury in the rat. Hypoactivity of spinal motoneurons is sufficient to induce this increase in mRNA - that is, it is 'inactivitydependent'; 50 thus injury to suprasegmental axons is not required. Other receptors (ie serotonin 2A, vanilloid VR1) also increase in density by 1-3 days caudal to spinal cord transection. ${ }^{53,54}$ Such trans criptional/translational increases in neurotransmitter receptors could explain the initial re-emergence of reflexes. Receptor plasticity over 1-3 days post-SCI may underlie re-emergence of cutaneous reflexes in cats and humans, ${ }^{7,55}$ tibial H-reflexes by $24 \mathrm{~h}$ in rats and humans, ${ }^{28,33,34,56}$ and anal reflexes in rats and humans. ${ }^{7,57}$

Neurotrophins (NTs), other growth factors (GFs), and their receptors (NT-Rs and GF-Rs) also undergo transcription-translation increases in expression by 1-3 days postinjury. This accompanies the transcriptiontranslation increase in neurotransmitter receptors. Selective increases in some factors and receptors are seen in both neurons and glia. ${ }^{58-63}$ The signal that triggers increased expression of NTs, GFs, and NT-Rs and GF-Rs is unknown, ${ }^{64}$ but lipopolysaccharides from degenerating axons or cytokine release by glia are candidates, as is spinal neuron inactivity. ${ }^{65}$

Administration of NTs and GFs has a range of effects. Some increase synaptic efficacy by increasing NMDA excitability, perhaps by phosphorylating the NR2A subunit of the NMDA-gated ionic channel. ${ }^{64,66,67}$ Others decrease GABA synaptic inhibition acutely. ${ }^{64}$ The enhancement of excitatory synapses and reduction of synaptic inhibition may contribute, along with receptor upregulation, to the emergence from spinal shock by 1-3 days postinjury.

Replacement of synapses is likely too slow to explain early reflex changes at 1-3 days. Although morphological changes have been noted in synapses within hours to days of SCI, ${ }^{6,69}$ restored synapses may not be functional until weeks to months after CNS trauma. ${ }^{70-73}$ Thus, early reflex changes are likely to be due to a postsynaptic change such as denervation supersensitivity.

\section{Phase 3: early hyper-reflexia (4 days to 1 month)}

\section{Clinical description 4-30 days}

The third phase of spinal shock extends from approximately 4 days to 1 month. Most DTRs first reappear during this period, ${ }^{7}$ and they are evident in almost all subjects within 30 days. The AJ usually precedes the KJ. ${ }^{7,38}$ The Babinski sign follows the recovery of the AJ very closely. Cutaneous reflexes (BC, AW, and CM) typically have appeared by the end of this period and only $10 \%$ of DPRs will persist beyond a month. Despite these general trends, the timing of reflex return is variable even after complete SCI where a uniform temporal course might be expected. Thus, 33\% of those with complete SCI develop an AJ by 1-3 days, $11 \%$ by 4-7 days, $41 \%$ by $8-14$ days, and $11 \%$ by $15-21$ days. $^{7}$ Some variability is likely due to differences in reflex excitability among able-bodied subjects. For example, tendon reflex excitability is reduced in ballet dancers, sprinters, and power-trained athletes ${ }^{74-76}$ compared to endurance-trained athletes and untrained individuals. These training effects are similar to the effects of operant conditioning in rats, monkeys, and humans, in which H-reflex amplitude can be increased or decreased over a period of days and weeks. ${ }^{11}$ Reflex excitability below a SCI may therefore be affected by pre-SCI experience, ${ }^{77,78}$ causing $\mathrm{AJ}$ to return later in a ballet dancer with low tendon reflex excitability than in an untrained individual.

Autonomic function continues to evolve with improvement in vagally mediated bradyarrhythmias and hypotension. Autonomic dysreflexia can begin to emerge. This is usually due to a distended viscus (eg, bladder or bowel) acting as a stimulus causing massive sympathetic outflow below the zone of injury, which is unregulated by supraspinal input. One case report ${ }^{79}$ suggested that autonomic dysreflexia may occur as early as 7 days after a complete injury, but the general time course of its development requires further study.

\section{Physiology 4-30 days}

Potential mechanisms are discussed in the next section on Phase 4 recovery.

\section{Phase 4: spasticity/hyper-reflexia (1-12 months)}

\section{Clinical description}

The fourth phase of spinal shock occurs between 1 and 6 months postinjury. The DPR has disappeared in the majority of cases. Cutaneous reflexes, DTRs, and the BS become hyperactive and respond to minimal stimuli. A review of the clinical literature fails to reveal any reported documentation of the course of recovery of detrusor paralysis; however, most clinicians would estimate the time of bladder recovery determined by cystometrogram to be 4-6 weeks. ${ }^{80}$ Reports from acute care settings show that vasovagal hypotension and bradyarrhythmias resolve in 3-6 weeks. ${ }^{81,82}$ Orthostatic hypotension as a result of standing a tetraplegia subject, 
however, may persist for $10-12$ weeks or longer. ${ }^{83} \mathrm{In}$ contrast, the malignant hypertension of autonomic dysreflexia develops by weeks to months and persists indefinitely.

Physiology 4 days -4 weeks: synapse growth, short axons and/or axon supplied; 1-12 months: synapse growth, long axons and soma supplied

Below a spinal cord lesion, synaptic endings from axotomized neurons to spinal motor neurons and interneurons degenerate over days and are then replaced by terminal sprouting from neurons below the lesion over weeks to months. ${ }^{16,17,31,84}$ Replacement synaptic growth may originate from both spinal interneurons and from primary segmental afferents. ${ }^{16,17,85-87}$ A postulated signal for new synaptic growth is the increase in NTs caudal to a SCI. BDNF, CNTF, and possibly NGF and NT-3 mRNA transcription peaks at several days postSCI and then gradually wanes, with expression in neurons and glia. ${ }^{58-61}$ NTs are released by hypoactive spinal neurons and are thus candidates for a retrograde signal to induce new synapse growth by reflex afferents over a time-course of weeks to months. ${ }^{87-90} \mathrm{New}$ synapse growth by dorsal root afferents can be blocked by intrathecal infusion of antibody to $\mathrm{NGF}^{88}$ and enhanced by intrathecal infusion of other NTs. ${ }^{90}$ Thus, NT-mediated synapse growth by primary segmental afferents in the isolated caudal spinal cord could possibly contribute to late developing spinal hyper-reflexia.

Viewed as a model for reflex recovery, human tibial H-reflex undergoes sequential changes caudal to spinal cord transection: (1) areflexia due to motoneuron hyperpolarization, (2) reflex re-emergence by 1-3 days due to neuronal transcription-translation yielding denervation supersenshivity, (3) increased reflex excitability at 2-4 weeks and increased latency at 1-4 weeks via disynaptic interneuron or axon-supplied synapse growth, and (4) increased reflex excitability at 3-4 months via primary afferent or soma-supplied synapse growth with less presynaptic inhibition and less H-reflex depression with repetitive stimulation. An axon-lengthdependent rate of synapse growth would explain the two phases of increased H-reflex excitability at 2-4 weeks and at 3-4 months. Axon-length-dependent rate of synapse growth would also explain the late appearance of extensor spasms and also interspecies differences in late return of the tibial H-reflex.

As stated above, human tibial H-reflex excitability increases after SCI during weeks $2-4$ and then again during months 3-4 (Figure 1). The H-reflex latency also increases by $2-4 \mathrm{~ms}$ at $1-4$ weeks and persists through the later reflex excitability increase at 3-4 months (Figure 1). The latter increase in H-reflex excitability is also associated with less presynaptic inhibition and less depression with repetitive stimulation. ${ }^{91}$ Distinct mechanisms are probably responsible for the two phases of increased H-reflex excitability. One theory is that disynaptic stretch reflex pathways become preferentially

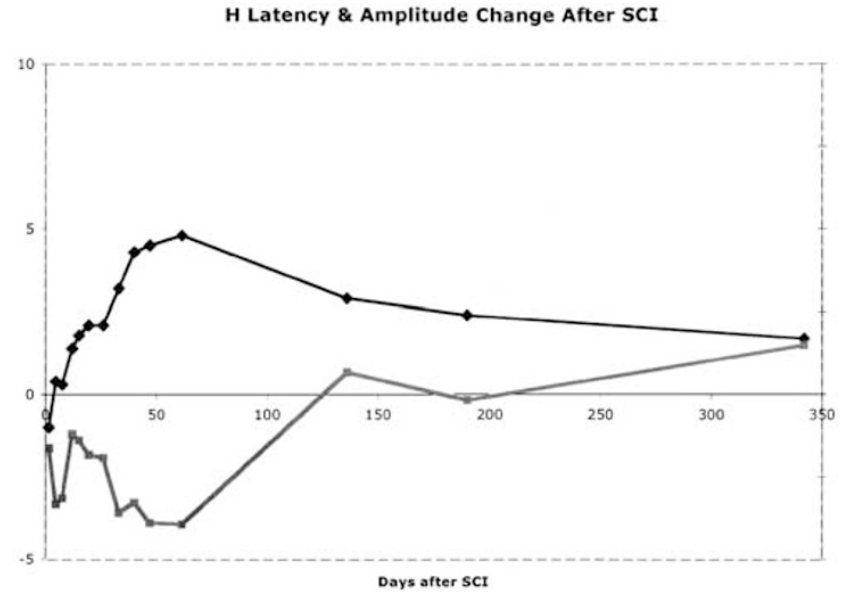

Figure 1 H-reflex amplitude and latency changes after SCI. Tibial H-reflex amplitude (bottom-gray) and latency (topblack) are plotted versus day after SCI for four lower limbs in two subjects with traumatic complete paraplegia. Data from all four limbs were averaged for each time period. Amplitude was measured as $\mathrm{H} / \mathrm{M}$ amplitude ratio and is shown as a percent difference from the mean $\mathrm{H} / \mathrm{M}$ amplitude ratio measured from able-bodied subjects. H-reflex and M-response amplitudes were recorded at measured sites over the soleus muscle. Latency is shown as a difference in milliseconds from able-bodied subjects with comparable reflex length for $\mathrm{H}-\mathrm{M}$ latency (ie latency of the tibial H-reflex minus the latency of the tibial M-response). Note that $\mathrm{H}$-latency is subnormal on days 3-4 and then increases during weeks 2-4 as $\mathrm{H}$-amplitude transiently increases; $\mathrm{H}$-amplitude markedly increases during months 3-4. Such serial quantitative observations of the tibial $\mathrm{H}$-reflex should be undertaken in a larger number of acute SCI subjects

hyperexcitable compared to the usual monosynaptic pathway from IA afferent to motoneuron; this could explain the persisting increase in H-reflex latency. Although the H-reflex and Achilles tendon reflex are traditionally considered monosynaptic reflexes, Burke et $a l^{92}$ suggest that disynaptic input contributes as well. Thus, spinal cord interneurons conveying IA input may initially form new synapses at 2-4 weeks and the IA afferents may grow synapses later at 3-4 months. The longer time course for synapse growth by IA afferents than interneurons could be explained by greater axon length (ie the length of the S1 dorsal root from sensory neuron cell bodies in the S1 neuroforamina of the sacrum to $\mathrm{S} 1$ segmental axon terminations in the spinal cord at about the L1 vertebral level). A second theory is that there could be two periods of synapse growth: initial growth dependent on axonal synthesis and later growth dependent on somal synthesis with axonal transport.

Whether either or both of these two potential mechanisms contribute to changes in the human tibial H-reflex below a SCI is unclear. Sequential synapse growth by interneurons followed by growth by primary afferents readily explains the observed increase in $\mathrm{H}$ reflex latency. Sequential synapse formation mediated 
by axonal and then somal phases could result in increased H-reflex latency due to persisting slowed conduction in thinner, immature terminal branches. The second theory is favored by the fact that H-reflex depression with repetitive stimulation is less in chronic SCI persons ( $>3$ months post-SCI) compared to acute subjects. ${ }^{93}$ This has been attributed to the maturing of terminal branches in chronic subjects. An additional advantage of the second theory is that an axon phase of synapse growth might serve a place-holding function, allowing the long-axoned neurons to, at least partially, compete with short-axoned neurons. It is also possible that both theories contribute to H-reflex changes in SCI patients.

Both theories require that the timing of synapse growth be axon-length-dependent. Axon growth and maintenance depend on fast and slow axonal transport of protein synthesized in the neuron soma. In the CNS, slow axonal transport rates range from 0.4 to $2 \mathrm{~mm} /$ day. ${ }^{94}$ If retrograde axonal transport of NTs (or other relay messengers) and anterograde axonal transport are required for most synapse growth, and if either or both involve slow transport, then axons of markedly differing length will achieve effective synapse growth at markedly differing rates. Of note, human S1 primary afferents have axon lengths of roughly $150 \mathrm{~mm}$ versus spinal interneurons with axon lengths of roughly $15 \mathrm{~mm}$.

In comparison to somal-mediated growth, some synapse growth originates from protein synthesis in axon terminals - a 'distributed sprouting program'. ${ }^{95-97}$ Growth cones have 500-1000 ribosomes that provide a low basal level of protein synthesis, but which yield a marked increase in local protein synthesis in response to NTs. Additional neurite extension could occur by the cannibalization of lipids and proteins from the proximal axon via the ubiquitin-proteosome pathway - that is, a localized redistribution of axonal membrane to allow compensatory synapse growth after CNS injury. New synapse growth by spinal reflex afferents mediating hyper-reflexia may occur initially via local axonal protein synthesis and local redistribution of axonal structural protein and then subsequently via somal protein synthesis with axonal transport of that protein. Initial synapse growth allows place holding by long axons, which would otherwise not be able to compete with intrinsic spinal interneurons for vacant synaptic sites. Later, more robust synapse growth could be achieved via an increased amount of slow axonal transport, triggered by retrograde transport of second messengers (eg $\mathrm{Ca}^{2+}$, InsP3, cAMP) or of endosomes containing neurotrophin-receptor complex (eg NGFTrkA, BDNF-TrkB, NT3-TrkC). ${ }^{89,98-100}$ Such retrograde signals alter gene expression in the nucleus with increased mRNA transcription, increased protein synthesis, and increased amounts of slow axonal transport. ${ }^{101}$ This increased amount of slow axonal transport would include both structural proteins (eg actin, tubulin) and assembled functional subunits (eg ion channel complexes, signaling complexes, etc.). ${ }^{101}$
Axon-length-dependent rate of late synapse growth may also explain markedly differing late reflex changes across species and across differing spinal reflexes. Rat and cat tibial H-reflexes undergo late changes as in humans, except that this late phase is seen at 3-4 weeks in the rat, ${ }^{102-104}$ at $4-6$ weeks in the cat, ${ }^{55}$ and at $12-16$ weeks in the human. ${ }^{105}$ Shorter-length IA axons in rats and cats would explain shorter times for late reflex change, presumably due to a dependence on retrograde signaling to the soma and slow anterograde axonal transport. Other observations suggest that the timing of late reflex changes relates to axon length. Hyperactive flexor reflexes yield flexor spasms by 1-3 months after SCI, whereas hyperactive stretch reflexes yield extensor spasms by 3-6 months $37,105,106$ and interlimb hyperreflexia by $6-12$ months; ${ }^{107}$ spinal interneurons have shorter axon lengths than the long central processes of IA afferent axons and the long interlimb axons. In cats with spinal cord transection, the latest changes in cutaneomuscular hyper-reflexia also precede the latest changes in tibial H-reflex hyper-reflexia; ${ }^{55}$ again, this suggests earlier synapse growth in short-axoned spinal interneurons relaying cutaneomuscular reflexes than in long-axoned Ia afferents relaying the tibial H-reflex.

Plateau potentials are an alternative neuronal mechanism to explain late hyper-reflexia. Low spinal cord transection at $\mathrm{S} 2$ in rat yields an areflexic tail that persists for 2 weeks; the tail then gradually becomes hyper-reflexic to both stretch and cutaneous stimuli. ${ }^{108}$ Spinal motoneurons below a transection show lowthreshold, prolonged, self-sustained motor-unit firing (minutes to hours) in association with hyper-reflexia; this hyperexcitable motoneuron behavior is present by 30 days after cord transection in rats but not at 2 days. $^{23,108}$ The late appearance of plateau potentials below SCI is proposed as a factor in late developing hyper-reflexia. Plateau potentials may result from synthesis of new ionic channels yielding recruitment of new voltage-activated calcium conductance. ${ }^{109}$ Plateau potentials may contribute to late hyper-reflexia, but protracted synapse growth, dependent on slow axonal transport, perhaps better explains an axon-lengthdependent time-course of reflex changes.

\section{Clinical implications of spinal shock}

\section{Competitive synapse growth and clinical outcomes}

Following SCI, new synapses may be formed by spinal interneurons, spinal reflex afferents, and spared supraspinal inputs. ${ }^{1+}$ The formation of new synapses could lead to both desirable and undesirable clinical effects. With significant sparing of descending motor input, descending axons can sprout, resulting in motor recovery. ${ }^{10}$ If there is minimal sparing of descending motor input, growth of segmental reflex inputs might instead contribute to spasticity and less voluntary motor recovery. This would be compatible with the theory of competitive synapse growth underlying functional recovery and hyper-reflexia. ${ }^{111}$ The quality of functional 
recovery would depend largely on the variety and number of descending motor axons spared. Preserved descending input after incomplete SCI allows some recovery of function, perhaps by the same neuronal mechanisms of denervation supersensitivity and synapse growth that allow the transition from areflexia to hyperreflexia. ${ }^{111}$

Both corticospinal inputs and IA afferents increase axon growth in response to the neurotrophin NT3. ${ }^{90,112-116}$ NTs like NT3, promoting both IA afferent and corticospinal neurite growth, could underlie competitive synapse growth. In subjects with chronic incomplete SCI and hyper-reflexia, motor neurons are often either under voluntary control or under reflex control; thus, either one or the other input comes to dominate control over a given motor neuron. In spastic muscles, these motor neurons may segregate into either reflex-controlled or voluntarily controlled. ${ }^{107} \mathrm{SCI}$ neuropathic pain may be another undesirable effect of new synapse growth by spinal afferents on pain relay neurons in the dorsal horn. ${ }^{87,117}$

Electrical activation promotes synaptic maturation and refinement of neural circuits. ${ }^{118}$ Selected activity and accompanying electrical activation might, therefore, be a method for selecting desired synapse growth. Recovery of voluntary function below incomplete SCI is probably enhanced by activity in both animals ${ }^{119}$ and humans. ${ }^{120}$ Exercise can increase NT synthesis in neurons of the spinal cord (BDNF, NT-4) 121 $^{121}$ and could be the molecular signal for such activity-dependent recovery. Functional recovery can occur with sprouting and synapse formation from spared descending motor axons. ${ }^{110}$ This is accompanied by successful depolarization of lower motor neurons despite reduced numbers of descending motor axons. The key to optimizing recovery of voluntary movement may be correlated activity of descending input and postsynaptic neurons $;{ }^{89}$ activity in descending inputs without correlated postsynaptic activity or vice versa may lead to weakening rather than strengthening of existing synapses.

The central pattern generator (CPG) in the lumbosacral spinal cord is a network of interneurons that facilitate the stereotypic, multijoint, rhythmic, and alternating movements involved in stepping. ${ }^{122-124}$ The CPG allows coordinated treadmill locomotion in cats with a transected thoracic spinal cord. ${ }^{125-127}$ In humans, gait training may promote synapse formation in the CPG. There is evidence in animals ${ }^{125-129}$ and humans ${ }^{120,130-137}$ that such an approach is beneficial. It is also of interest that training is specific in that animals trained to stand eventually weight bear on the hindlimbs but do not step; likewise, step training produces the opposite effect. A multi center trial to evaluate the efficacy of weight-supported gait training in humans is underway. Such training may be enhanced by medications such as the noradrenergic $\alpha$-2-agonist clonidine. ${ }^{138,139}$

Functional electrical stimulation is an alternative method for stimulating specific synapses and neuron pools, therefore influencing spinal cord plasticity and performance. ${ }^{140-142}$ Additional interventions that might enhance synapse formation by spared descending inputs include medications to increase excitability of spinal neurons (eg 5-HTP, clonidine, TRH, and theophylline), ${ }^{54,143-145}$ stimulants of axon growth (eg inosine), ${ }^{146}$ stimulants of NT synthesis (eg clenbuterol), ${ }^{147,148}$ inhibitors of Nogo and related myelin glycoproteins that block longer-distance axon sprouting, ${ }^{149}$ and agents that block the intracellular Rho pathway, which inhibits axon growth. ${ }^{150}$ Adding these interventions in combination with exercise therapies might have a synergistic effect on activity-dependent synapse growth. This might also aid selective synapse growth by desired axon populations as specific NTs work on different groups of axons. ${ }^{151}$ During the recovery period, clinicians must also strive to optimize conditions for new synapse growth, which includes optimizing nutrition, optimizing general health, and minimizing medication use that may compromise synapse growth. ${ }^{152}$

In contrast to promoting synapse formation by descending motor pathways, an alternative approach is to inhibit synapse growth by segmental reflex inputs. Synapse growth by reflex afferents may interfere with synapse growth by descending motor pathways. In cats with a spinal hemisection, dorsal root projections extend into areas normally innervated by corticospinal, reticulospinal, rubrospinal, and vestibulospinal tracts. ${ }^{17}$ Suppressing hyper-reflexia or minimizing its development may be necessary to optimize functional recovery. ${ }^{11,152,153}$

\section{Timing of potential interventions}

Competitive synapse growth has important implications for the timing of interventions. Following SCI, synaptic spaces are vacated by degenerating axons and later repopulated by new synapses from spared axons. Critical periods may be due to a transient period when many vacant synaptic sites are open to innervation by spared inputs. An intervention targeted at promoting synapse growth by axons mediating voluntary movement should be applied before available synapse space is occupied by synapses from local segmental neurons mediating spasticity and hyper-reflexia. The optimal timing likely differs between complete and incomplete SCI.

In complete SCI, any regenerating axons of descending motor pathways are at a disadvantage due to axon length. Soma-supported synapse growth in supraspinal axons, originating in brainstem or cerebral cortex, would be limited by slow axonal transport. Regenerating corticospinal or bulbospinal axons may need to regenerate significant distances to reach target populations of spinal neurons. Considerable success has been reported recently in promoting regeneration of supraspinal axons, by using Schwann cell endoneurial tubes or olfactory ensheathing cells or by blocking innate inhibitors of spinal axon regeneration. ${ }^{149-151}$ However, for these regenerating axons to achieve sufficient functional synapses with spinal neurons, it may be necessary to inhibit undesirable synapse growth by 
segmental reflex inputs or it may be necessary to open up vacant synaptic sites as regenerating axons enter the caudal cord. Clinicians may need to 'destabilize' newly grown synapses by intrinsic spinal neurons to allow regenerating descending axons to establish new synapses. ${ }^{11}$ This might be accomplished by using botulinum toxin or alcohol injected intramuscularly for 'somatic stripping' of synapses on motor neuron soma. ${ }^{154} \mathrm{NT}$ administration or in vivo synthesis may then be required to assure synapse formation by the regenerated axons.

For incomplete SCI, with significant axonal sparing, descending motor axons are present to compete with segmental reflex inputs. Marked species differences (human, monkey, cat, rat) have been observed in the time-course of functional recovery after incomplete SCI, as well as in the full appearance of spinal hyper-reflexia after complete SCI. ${ }^{105,111,119,155,156}$ Traditionally, this was attributed to varying degrees of encephalization across species, but it may actually reflect the longer delay for soma-supported synapse growth in the human and monkey due to longer axons. The timing of acute rehabilitation should be targeted to optimize synapse growth by spared supraspinal inputs and to minimize interfering growth by segmental inputs. Functional desirable new synapse growth can then be reinforced and allowed to mature through soma-supported synapse growth. The utilization of growth factors as well as specialized training that selectively stimulates descending motor pathways might make this approach feasible.

\section{Future research on spinal shock}

The proposed model of spinal shock suggests several questions for clinician investigators: Can a quantitative clinical study of spinal reflexes from day 0 to day 365 post-SCI reveal more details of the underlying neuronal mechanisms, similar to $\mathrm{Ko}$ et $a l^{7}$ but relying on quantitative measures? Is overshoot in spinal reflexes noted, as is expected if denervation supersensitivity overlaps with new synapse growth for several days, until supersensitivity wanes? ${ }^{54,111}$ Does the latest phase of hyper-reflexia for the patellar tendon reflex (L3 afferent, L3 efferent) precede the latest phase of hyper-reflexia for the Achilles tendon reflex ( $\mathrm{S} 1$ afferent, $\mathrm{S} 1$ efferent) given that the axon length is much less for patellar than Achilles reflex? Studies to address these questions will help refine the proposed model of spinal shock or may suggest an alternative model.

\section{Conclusion}

Spinal shock has been known for over two centuries. Its hallmark is the transient suppression and gradual return of reflex activity caudal to SCI. Despite abiding interest by clinicians and physiologists, underlying neuronal mechanisms and clinical significance of spinal shock have remained controversial, until recently. With the exponential growth in new knowledge regarding postinjury spinal cord physiology comes an increased understanding of this complex clinical process. We present here a new paradigm for spinal shock consisting of four phases: (1) areflexia/hyporeflexia, (2) initial reflex return, (3) early hyper-reflexia, and (4) late hyperreflexia. It is increasingly apparent that spinal shock reflects underlying neuroplasticity after SCI. Denervation supersensitivity in partially denervated spinal neurons allows initial return of spinal reflexes by 1-3 days. Over subsequent weeks and months, reflex axons grow new synapses to mediate hyper-reflexia; the timecourse is protracted for full evolution of the hyperreflexia because the synapse growth appears to be, in part, axon-length-dependent. The synapse growth is also likely activity-dependent and competitive. Understanding these processes provides us with opportunities to modulate spinal cord plasticity, thereby enhancing desired outcomes while minimizing maladaptive responses. Herein is the true significance of spinal shock.

\section{Acknowledgements}

We thank Dr Marion Murray, Professor, Department of Neurobiology and Anatomy, Drexel University College of Medicine for her critical reading of the manuscript. Dr Ditunno's research is supported in part under Grant \#H133N000023 from the National Institute on Disability and Rehabilitation Research, Office of Special Education and Rehabilitative Services, US Department of Education, Washington, DC. Dr Little's research is supported by the Department of Veterans Affairs and the American Paraplegia Society. Dr Burns' research is supported by Grant $2 \mathrm{~K} 12$ HDO197-6 from the Rehabilitation Medicine Scientist Training Program (RMSTP), National Institute of Child Health and Human Development, National Institutes of Health, Washington, DC. Dr Tessler's research is supported by the Research Service of the Department of Veterans Affairs, NIH Grant NS24707, Eastern Paralyzed Veterans Association, International Spinal Cord Research Trust and a Center of Excellence Grant from Drexel University College of Medicine.

\section{References}

1 Sherrington CS. The Integrative Action of the Nervous System. Constable \& Company LTD: London, 1906.

2 Hall M. Synopsis of the Diastaltic Nervous System: or The System of the Spinal Marrow, and its Reflex Arcs; as the Nervous Agent in all the Functions of Ingestion and of Egestion in the Animal Oeconomy. Mallett J.: London, 1850 .

3 van Gijn J. The Babinski Sign - a Centenary. University Utretcht: Utrecht, 1996.

4 White RJ, Likavec MJ. Spinal shock - spinal man. $J$ Trauma 1999; 46: 979-980.

5 Nacimiento W, Noth J. What, if anything, is spinal shock? Arch Neurol 1999; 56: 1033-1035.

6 Atkinson PP, Atkinson JL. Spinal shock. Mayo Clin Proc 1996; 71: 384-389.

7 Ko HY, Ditunno Jr JF, Graziani V, Little JW. The pattern of reflex recovery during spinal shock. Spinal Cord 1999; 37: 402-409.

8 Sherrington CS. Croonian Lecture (1897): the mammalian spinal cord as an organ of reflex action. Philos Trans 1898; 190B: $128-138$. 
9 Holdsworth FW. Neurological diagnosis and the indications for treatment of paraplegia and tetraplegia, associated with fractures of the spine. Manit Med Rev 1968; 48: $16-18$.

10 Stauffer ES. Diagnosis and prognosis of acute cervical spinal cord injury. Clin 1975; 112: 9-15.

11 Wolpaw JR, Tennissen AM. Activity-dependent spinal cord plasticity in health and disease. Annu Rev Neurosci 2001; 24: 807-843.

12 Hiersemenzel LP, Curt A, Dietz V. From spinal shock to spasticity: neuronal adaptations to a spinal cord injury. Neurology 2000; 54: 1574-1582.

13 Guttmann L. Studies on reflex activity of the isolated cord in spinal man. J Nerv Ment Dis 1952; 116: 957-972.

14 Illis LS. Clinical evaluation and pathophysiology of the spinal cord in the chronic phase. In: Illis LS (ed.) Spinal Cord Dysfunction. Oxford University Press: New York, 1988, pp 107-128.

15 Guillain G, Barre JA. Etude anatomo-clinique de quinze cas de section totalle de la moelle. Ann Med 1917; 4: 178-222.

16 Goldberger ME, Murray M. Patterns of sprouting and implications for recovery of function. Adv Neurol 1988; 47: 361-385; (review).

17 Murray M, Goldberger ME. Restitution of function and collateral sprouting in the cat spinal cord: the partially hemisected animal. J Comp Neurol 1974; 158: $19-36$.

18 Schadt JC, Barnes CD. Motoneuron membrane changes associated with spinal shock and the Schiff-Sherrington phenomenon. Brain Res 1980; 201: 373-383.

19 Miller JF, Paul KD, Lee RH, Rymer WZ, Heckman CJ. Restoration of extensor excitability in the acute spinal cat by the 5-HT2 agonist DOI. J Neurophysiol 1996; 75: $620-628$.

20 Lee RH, Heckman CJ. Adjustable amplification of synaptic input in the dendrites of spinal motoneurons in vivo. J Neurosci 2000; 20: 6734-6740.

21 Machacek DW, Garraway SM, Shay BL, Hochman S. Serotonin 5-HT(2) receptor activation induces a longlasting amplification of spinal reflex actions in the rat. J Physiol 2001; 537: 201-207.

22 Alaburda A, Perrier JF, Hounsgaard J. Mechanisms causing plateau potentials in spinal motoneurones. $A d v$ Exp Med Biol 2002; 508: 219-226.

23 Bennett DJ, Li Y, Siu M. Plateau potentials in sacrocaudal motoneurons of chronic spinal rats, recorded in vitro. J Neurophysiol 2001; 86: 1955-1971.

24 Binder MD, Heckman CJ, Powers RK. Relative strengths and distributions of different sources of synaptic input to the motoneurone pool: implications for motor unit recruitment. Adv Exp Med Biol 2002; 508: 207-212.

25 Weaver RA, Landau WM, Higgins JF. Fusimotor function. II. Evidence of fusimotor function in human spinal shock. Arch Neurol 1963; 9: 127-132.

26 Zapata P. Peripheral and central factors in the pathophysiology of spinal shock. Acta Physiol Lat Am 1966; 16: $266-277$.

27 Ashby P, Verrier M, Lightfoot E. Segmental reflex pathways in spinal shock and spinal spasticity in man. $J$ Neurol Neurosurg Psychiatry 1974; 37: 1352-1360.

28 Chen XY, Feng-Chen KC, Chen L, Stark DM, Wolpaw JR. Short-term and medium-term effects of spinal cord tract transections on soleus H-reflex in freely moving rats. J Neurotrauma 2001; 18: 313-327.
29 Simpson Jr RK, Robertson CS, Goodman JC. The role of glycine in spinal shock. J Spinal Cord Med 1996; 19: $215-224$.

30 Schwartzman RJ, Eidelberg E, Alexander GM, Yu J. Regional metabolic changes in the spinal cord related to spinal shock and later hyperreflexia in monkeys. Ann Neurol 1983; 14: 33-37.

31 Illis LS. The motor neuron surface and spinal shock. Mod Trends Neurol 1967; 4: 53-68.

32 Llewellyn-Smith IJ, Weaver LC. Changes in synaptic inputs to sympathetic preganglionic neurons after spinal cord injury. J Comp Neurol 2001; 435: 226-240.

33 Cadilhac J, Georgesco M, Benezech J, Duday H, Dapres G. Somatosensory evoked potentials and Hoffmann reflex in acute spinal cord lesions; physiopathological and prognostic aspects. Electroencephalogr din Neurophysiol 1977; 43: 160-167.

34 Leis AA, Zhou HH, Mehta M, Harkey III HL, Paske WC. Behavior of the H-reflex in humans following mechanical perturbation or injury to rostral spinal cord. Muscle Nerve 1996; 19: 1373-1382.

35 Burke D. Critical examination of the case for or against fusimotor involvement in disorders of muscle tone. In: Desmedt JE (ed.) Motor Control Mechanisms in Health and Disease. Advances in Neurology. Raven Press: New York, 1983, pp 133-150.

36 Liu CM, Chambers WW, McCouch GP. Reflexes in the spinal monkey (Macaca mulatta). Brain 1966; 89: $349-358$.

37 Riddoch $\mathrm{G}$. The reflex functions of the completely divided spinal cord in man, compared with those associated with less severe lesions. Brain 1917; 40: 264-401.

38 Guttmann L. Spinal shock. In: Vinken PJ, Bryun GW (eds.) Injuries to the Spine and Spinal Cord. Part II. North-Holland Publishing Co: Amsterdam, 1976, pp 243-262.

39 Cannon WB, Haimovici H. The sensitization of motoneurons by partial denervation. Am J Physiol 1939; 126: $731-740$.

40 Burke D. Spasticity as an adaptation to pyramidal tract injury. In: Waxman SG (ed.) Functional Recovery in Neurological Disease. Raven Press: New York, 1988, pp 401-423.

41 Bach-y-Rita P, Illis LS. Spinal shock: possible role of receptor plasticity and nonsynaptic transmission. Paraplegia 1993; 31: 82-87.

42 Vita G, Haun CK, Hawkins EF, Engel WK. Autoradiographic localization of substance $P$ receptors in rat spinal cord: effects of experimental spinal transection. Funct Neurol 1987; 2: 421-426.

43 Brown LM, Smith DL, Williams GM, Smith DJ. Alterations in serotonin binding sites after 5,7-dihydroxytryptamine treatment in the rat spinal cord. Neurosci Lett 1989; 102: 103-107.

44 Kroin JS, Bianchi GD, Penn RD. Spinal cord transection produces a long-term increase in GABAB binding in the rat substantia gelatinosa. Synapse 1993; 14: 263-267.

45 Roudet C, Savasta M, Feuerstein C. Normal distribution of alpha-1-adrenoceptors in the rat spinal cord and its modification after noradrenergic denervation: a quantitative autoradiographic study. $J$ Neurosci Res 1993; 34: 44-53.

46 Sawynok J, Reid A. Spinal supersensitivity to 5-HT1, 5HT2 and 5-HT3 receptor agonists following 5,7-dihydroxytryptamine. Eur J Pharmacol 1994; 264: 249-257. 
47 Barry MF, Ziff EB. Receptor trafficking and the plasticity of excitatory synapses. Curr Opin Neurobiol 2002; 12: 279-286.

48 Ehlers MD. Activity level controls postsynaptic composition and signaling via the ubiquitin-proteasome system. Nat Neurosci 2003; 6: 231-242.

49 Grossman SD, Rosenberg LJ, Wrathall JR. Relationship of altered glutamate receptor subunit mRNA expression to acute cell loss after spinal cord contusion. Exp Neurol 2001; 168: 283-289.

50 Grossman SD, Wrathall JR. The role of activity blockade on glutamate receptor subunit expression in the spinal cord. Brain Res 2000; 880: 183-186.

51 Spitzer NC. New dimensions of neuronal plasticity. Nat Neurosci 1999; 2: 489-491.

52 Grossman SD, Wolfe BB, Yasuda RP, Wrathall JR. Changes in NMDA receptor subunit expression in response to contusive spinal cord injury. $J$ Neurochem 2000; 75: 174-184.

53 Basura GJ, Zhou SY, Walker PD, Goshgarian HG. Distribution of serotonin $2 \mathrm{~A}$ and $2 \mathrm{C}$ receptor mRNA expression in the cervical ventral horn and phrenic motoneurons following spinal cord hemisection. Exp Neurol 2001; 169: 255-263.

54 Zhou Y, Wang Y, Abdelhady M, Mourad MS, Hassouna MM. Change of vanilloid receptor 1 following neuromodulation in rats with spinal cord injury. J Surg Res 2002; 107: $140-144$.

55 Little JW. Serial recording of reflexes after feline spinal cord transection. Exp Neurol 1986; 93: 510-521.

56 Chen XY, Wolpaw JR. Probable corticospinal tract control of spinal cord plasticity in the rat. $J$ Neurophysiol 2002; 87: 645-652.

57 Holmes GM, Rogers RC, Bresnahan JC, Beattie MS. External anal sphincter hyperreflexia following spinal transection in the rat. $J$ Neurotrauma 1998; 15: 451-457.

58 Ikeda $\mathrm{O}$ et al. Acute up-regulation of brain-derived neurotrophic factor expression resulting from experimentally induced injury in the rat spinal cord. Acta Neuropathol (Berl) 2001; 102: 239-245.

59 Widenfalk J, Lundstromer K, Jubran M, Brene S, Olson L. Neurotrophic factors and receptors in the immature and adult spinal cord after mechanical injury or kainic acid. J Neurosci 2001; 21: 3457-3475.

60 Oyesiku NM, Wilcox JN, Wigston DJ. Changes in expression of ciliary neurotrophic factor (CNTF) and CNTF-receptor alpha after spinal cord injury. J Neurobiol 1997; 32: 251-261.

61 Hayashi M, Ueyama T, Nemoto K, Tamaki T, Senba E. Sequential mRNA expression for immediate early genes, cytokines, and neurotrophins in spinal cord injury. $J$ Neurotrauma 2000; 17: 203-218.

62 Nakamura M, Bregman BS. Differences in neurotrophic factor gene expression profiles between neonate and adult rat spinal cord after injury. Exp Neurol 2001; 169: $407-415$.

63 King VR, Bradbury EJ, McMahon SB, Priestley JV. Changes in truncated trkB and $\mathrm{p} 75$ receptor expression in the rat spinal cord following spinal cord hemisection and spinal cord hemisection plus neurotrophin treatment. Exp Neurol 2000; 165: 327-341.

64 Schinder AF, Poo M. The neurotrophin hypothesis for synaptic plasticity. Trends Neurosci 2000; 23: 639-645.

65 Miwa T, Furukawa S, Nakajima K, Furukawa Y, Kohsaka S. Lipopolysaccharide enhances synthesis of brain-derived neurotrophic factor in cultured rat microglia. J Neurosci Res 1997; 50: 1023-1029.

$66 \mathrm{Di}$ Luca $\mathrm{M}$ et al. NMDA receptor subunits are phosphorylated by activation of neurotrophin receptors in PSD of rat spinal cord. Neuroreport 2001; 12: $1301-1305$.

67 Mendell LM, Munson JB, Arvanian VL. Neurotrophins and synaptic plasticity in the mammalian spinal cord. $J$ Physiol 2001; 533: 91-97.

68 Goshgarian HG, Yu XJ, Rafols JA. Neuronal and glial changes in the rat phrenic nucleus occurring within hours after spinal cord injury. J Comp Neurol 1989; 284: 519-533.

69 Beattie MS, Leedy MG, Bresnahan JC. Evidence for alterations of synaptic inputs to sacral spinal reflex circuits after spinal cord transection in the cat. Exp Neurol 1993; 123: 35-50.

70 Masliah E, Pagan AM, Terry RD, DeTeresa R, Mallory M, Gage FH. Reactive synaptogenesis assessed by synaptophysin immunoreactivity is associated with GAP-43 in the dentate gyrus of the adult rat. Exp Neurol 1991; 113: 131-142.

71 Matthews DA, Cotman C, Lynch G. An electron microscopic study of lesion-induced synaptogenesis in the dentate gyrus of the adult rat. II. Reappearance of morphologically normal synaptic contacts. Brain Res 1976; 115: 23-41.

72 Reeves TM, Smith DC. Reinnervation of the dentate gyrus and recovery of alternation behavior following entorhinal cortex lesions. Behav Neurosci 1987; 101: 179-186.

73 Stroemer RP, Kent TA, Hulsebosch CE. Enhanced neocortical neural sprouting, synaptogenesis, and behavioral recovery with D-amphetamine therapy after neocortical infarction in rats. Stroke 1998; 29: 2381-2393.

74 Casabona A, Polizzi MC, Perciavalle V. Differences in Hreflex between athletes trained for explosive contractions and non-trained subjects. Eur J Appl Physiol Occup Physiol 1990; 61: 26-32.

75 Nielsen J, Crone C, Hultborn H. H-reflexes are smaller in dancers from The Royal Danish Ballet than in welltrained athletes. Eur J Appl Physiol Occup Physiol 1993; 66: $116-121$.

76 Maffiuletti NA, Martin A, Babault N, Pensini M, Lucas B, Schieppati M. Electrical and mechanical H(max)-to$\mathrm{M}(\max )$ ratio in power- and endurance-trained athletes. J Appl Physiol 2001; 90: 3-9.

77 Steinmetz JE, Beggs AL, Molea D, Patterson MM. Longterm retention of a peripherally induced flexor reflex alteration in rats. Brain Res 1985; 327: 312-315.

78 Kauppila T, Kontinen VK, Pertovaara A. Influence of spinalization on spinal withdrawal reflex responses varies depending on the submodality of the test stimulus and the experimental pathophysiological condition in the rat. Brain Res 1998; 797: 234-242.

79 Silver JR. Early autonomic dysreflexia. Spinal Cord 2000; 38: $229-233$.

80 Chancellor MB Personal communication, 2002.

81 Winslow EB, Lesch M, Talano JV, Meyer Jr PR. Spinal cord injuries associated with cardiopulmonary complications. Spine 1986; 11: 809-812.

82 Lehmann KG, Lane JG, Piepmeier JM, Batsford WP. Cardiovascular abnormalities accompanying acute spinal cord injury in humans: incidence, time course and severity. J Am Coll Cardiol 1987; 10: 46-52. 
83 Sampson EE, Burnham RS, Andrews BJ. Functional electrical stimulation effect on orthostatic hypotension after spinal cord injury. Arch Phys Med Rehabil 2000; 81: 139-143.

84 Tai Q, Palazzolo KL, Goshgarian HG. Synaptic plasticity of 5-hydroxytryptamine-immunoreactive terminals in the phrenic nucleus following spinal cord injury: a quantitative electron microscopic analysis. J Comp Neurol 1997; 386: $613-624$.

85 Helgren ME, Goldberger ME. The recovery of postural reflexes and locomotion following low thoracic hemisection in adult cats involves compensation by undamaged primary afferent pathways. Exp Neurol 1993; 123: 17-34.

86 Zhang B, Goldberger ME, Wu LF, Murray M. Plasticity of complex terminals in lamina II in partially deafferented spinal cord: the cat spared root preparation. Exp Neurol 1995; 132: 186-193.

87 Christensen MD, Hulsebosch CE. Spinal cord injury and anti-NGF treatment results in changes in CGRP density and distribution in the dorsal horn in the rat. Exp Neurol 1997; 147: 463-475.

88 Krenz NR, Weaver LC. Sprouting of primary afferent fibers after spinal cord transection in the rat. Neuroscience 1998; 85: 443-458.

89 Tao HW, Poo M. Retrograde signaling at central synapses. Proc Natl Acad Sci USA 2001; 98: 11009-11015.

90 Ramer MS et al. Neurotrophin-3-mediated regeneration and recovery of proprioception following dorsal rhizotomy. Mol Cell Neurosci 2002; 19: 239-249.

91 Schindler-Ivens S, Shields RK. Low frequency depression of H-reflexes in humans with acute and chronic spinalcord injury. Exp Brain Res 2000; 133: 233-241.

92 Burke D, Gandevia SC, McKeon B. Monosynaptic and oligosynaptic contributions to human ankle jerk and $\mathrm{H}$ reflex. J Neurophysiol 1984; 52: 435-448.

93 Calancie B, Broton JG, Klose KJ, Traad M, Difini J, Ayyar DR. Evidence that alterations in presynaptic inhibition contribute to segmental hypo- and hyperexcitability after spinal cord injury in man. Electroencephalogr Clin Neurophysiol 1993; 89: 177-186.

94 Oblinger MM. Biochemical composition and dynamics of the axonal cytoskeleton in the corticospinal system of the adult hamster. Metab Brain Dis 1988; 3: 49-65.

95 Campbell DS, Holt CE. Chemotropic responses of retinal growth cones mediated by rapid local protein synthesis and degradation. Neuron 2001; 32: 1013-1026.

96 Alvarez J, Giuditta A, Koenig E. Protein synthesis in axons and terminals: significance for maintenance, plasticity and regulation of phenotype. With a critique of slow transport theory. Prog Neurobiol 2000; 62: 1-62.

97 Brittis PA, Lu Q, Flanagan JG. Axonal protein synthesis provides a mechanism for localized regulation at an intermediate target. Cell 2002; 110: 223-235.

98 Ginty DD, Segal RA. Retrograde neurotrophin signaling: trk-ing along the axon. Curr Opin Neurobiol 2002; 12: 268-274.

99 Barker PA, Hussain NK, McPherson PS. Retrograde signaling by the neurotrophins follows a well-worn trk. Trends Neurosci 2002; 25: 379-381.

100 Fitzsimonds RM, Poo MM. Retrograde signaling in the development and modification of synapses. Physiol Rev 1998; 78: 143-170.

101 Muresan V. One axon, many kinesins: What's the logic? J Neurocytol 2000; 29: 799-818.
102 Thompson FJ, Reier PJ, Lucas CC, Parmer R. Altered patterns of reflex excitability subsequent to contusion injury of the rat spinal cord. J Neurophysiol 1992; 68: $1473-1486$.

103 Skinner RD, Houle JD, Reese NB, Berry CL, Garcia-Rill E. Effects of exercise and fetal spinal cord implants on the H-reflex in chronically spinalized adult rats. Brain Res 1996; 729: 127-131.

104 Bose P, Parmer R, Thompson FJ. Velocity-dependent ankle torque in rats after contusion injury of the midthoracic spinal cord: time course. $J$ Neurotrauma 2002; 19: 1231-1249.

105 Little JW, Halar EM. H-reflex changes following spinal cord injury. Arch Phys Med Rehabil 1985; 66: 19-22.

106 Kuhn RA. Functional capacity of the isolated human spinal cord. Brain 1950; 73: 1-51.

107 Calancie B, Molano MR, Broton JG. Interlimb reflexes and synaptic plasticity become evident months after human spinal cord injury. Brain 2002; 125: 1150-1161.

108 Bennett DJ, Gorassini M, Fouad K, Sanelli L, Han Y, Cheng J. Spasticity in rats with sacral spinal cord injury. J Neurotrauma 1999; 16: 69-84.

109 Schmidt BJ, Hochman S, MacLean JN. NMDA receptormediated oscillatory properties: potential role in rhythm generation in the mammalian spinal cord. Ann N Y Acad Sci 1998; 860: 189-202.

110 Weidner N, Ner A, Salimi N, Tuszynski MH. Spontaneous corticospinal axonal plasticity and functional recovery after adult central nervous system injury. Proc Natl Acad Sci USA 2001; 98: 3513-3518.

111 Little JW, Ditunno Jr JF, Stiens SA, Harris RM. Incomplete spinal cord injury: neuronal mechanisms of motor recovery and hyperreflexia. Arch Phys Med Rehabil 1999; 80: 587-599.

112 Schnell L, Schneider R, Kolbeck R, Barde YA, Schwab ME. Neurotrophin-3 enhances sprouting of corticospinal tract during development and after adult spinal cord lesion. Nature 1994; 367: 170-173.

113 Grill R, Murai K, Blesch A, Gage FH, Tuszynski MH. Cellular delivery of neurotrophin-3 promotes corticospinal axonal growth and partial functional recovery after spinal cord injury. J Neurosci 1997; 17: 5560-5572.

114 Jeffery ND, Fitzgerald M. Effects of red nucleus ablation and exogenous neurotrophin-3 on corticospinal axon terminal distribution in the adult rat. Neuroscience 2001; 104: 513-521.

115 Krylova O, Herreros J, Cleverley KE, Ehler E, Henriquez JP, Hughes SM, Salinas PC. WNT-3, expressed by motoneurons, regulates terminal arborization of neurotrophin-3-responsive spinal sensory neurons. Neuron 2002; 35: 1043-1056.

116 Chen HH, Tourtellotte WG, Frank E. Muscle spindlederived neurotrophin 3 regulates synaptic connectivity between muscle sensory and motor neurons. $J$ Neurosci 2002; 22: 3512-3519.

117 Kapfhammer JP. Axon sprouting in the spinal cord: growth promoting and growth inhibitory mechanisms. Anat Embryol (Berl) 1997; 196: 417-426.

118 Zhang LI, Poo MM. Electrical activity and development of neural circuits. Nat Neurosci 2001; 4(Suppl): 1207-1214.

119 Little JW, Harris RM, Lerner SJ. Immobilization impairs recovery after spinal cord injury. Arch Phys Med Rehabil 1991; 72: 408-412. 
120 Wernig A, Nanassy A, Muller S. Maintenance of locomotor abilities following Laufband (treadmill) therapy in para- and tetraplegic persons: follow-up studies. Spinal Cord 1998; 36: 744-749.

121 Skup M, Dwornik A, Macias M, Sulejczak D, Wiater M, Czarkowska-Bauch J. Long-term locomotor training upregulates $\operatorname{TrkB}(\mathrm{FL})$ receptor-like proteins, brain-derived neurotrophic factor, and neurotrophin 4 with different topographies of expression in oligodendroglia and neurons in the spinal cord. Exp Neurol 2002; 176: 289-307.

122 Rossignol S. Neural control of stereotypic limb movements. In: Rowell LB, Sheperd JT (eds.) Handbook of Physiology. Oxford University Press: New York, 1996, pp 173-216.

123 Orlovsky GN, Deliagina TG, Grillner S. Neuronal Control of Locomotion from Molusc to Man. Oxford University Press: New York, 1999.

124 Barbeau H, McCrea DA, O’Donovan MJ, Rossignol S, Grill WM, Lemay MA. Tapping into spinal circuits to restore motor function. Brain Res Rev 1999; 30: 27-51.

125 Barbeau H, Rossignol S. Recovery of locomotion after chronic spinalization in the adult cat. Brain Res 1987; 412: 84-95.

126 Shurrager PS, Dykman RA. Walking spinal carnivores. J Comp Physiol Psychol 1951; 44: 252-262.

127 Lovely RG, Gregor RJ, Roy RR, Edgerton VR. Effects of training on the recovery of full-weight-bearing stepping in the adult spinal cat. Exp Neurol 1986; 92: 421-435.

128 Belanger M, Drew T, Provencher J, Rossignol S. A comparison of treadmill locomotion in adult cats before and after spinal transection. $J$ Neurophysiol 1996; 76: 471-491.

129 de Leon RD, Hodgson JA, Roy RR, Edgerton VR. Locomotor capacity attributable to step training versus spontaneous recovery after spinalization in adult cats. J Neurophysiol 1998; 79: 1329-1340.

130 Wernig A, Muller S, Nanassy A, Cagol E. Laufband therapy based on 'rules of spinal locomotion' is effective in spinal cord injured persons. Eur $J$ Neurosci 1995; 7: 823-829.

131 Dietz V, Colombo G, Jensen L, Baumgartner L. Locomotor capacity of spinal cord in paraplegic patients. Ann Neurol 1995; 37: 574-582.

132 Dobkin BH. Activity-dependent learning contributes to motor recovery. Ann Neurol 1998; 44: 158-160.

133 Dobkin BH. An overview of treadmill locomotor training with partial body weight support: a neurophysiologically sound approach whose time has come for randomized clinical trials. Neurorehabil Neural Repair 1999; 13: 157-165.

134 Rossignol S. Locomotion and its recovery after spinal injury. Curr Opin Neurobiol 2000; 10: 708-716.

135 Barbeau H, Fung J. New experimental approaches in the treatment of spastic gait disorders. Med Sports Sci 1992; 36: $234-246$.

136 Harkema SJ, Hurley SL, Patel UK, Requejo PS, Dobkin $\mathrm{BH}$, Edgerton VR. Human lumbosacral spinal cord interprets loading during stepping. J Neurophysiol 1997; 77: 797-811.

137 Field-Fote EC. Spinal cord control of movement: implications for locomotor rehabilitation following spinal cord injury. Phys Ther 2000; 80: 477-484.

138 Chau C, Barbeau H, Rossignol S. Early locomotor training with clonidine in spinal cats. $J$ Neurophysiol 1998; 79: 392-409.
139 de Leon RD, Hodgson JA, Roy RR, Edgerton VR. Retention of hindlimb stepping ability in adult spinal cats after the cessation of step training. J Neurophysiol 1999; 81: 85-94.

140 Peckham PH, Creasey GH. Neural prostheses: clinical applications of functional electrical stimulation in spinal cord injury. Paraplegia 1992; 30: 96-101.

141 Muir GD, Steeves JD. Sensorimotor stimulation to improve locomotor recovery after spinal cord injury. Trends Neurosci 1997; 20: 72-77.

142 Stein RB. Functional electrical stimulation after spinal cord injury. J Neurotrauma 1999; 16: 713-717.

143 Tremblay LE, Bedard PJ. Action of 5-hydroxytryptamine, substance $\mathrm{P}$, thyrotropin releasing hormone and clonidine on spinal neuron excitability. J Spinal Cord Med 1995; 18: 42-46.

144 Feraboli-Lohnherr D, Barthe JY, Orsal D. Serotonininduced activation of the network for locomotion in adult spinal rats. J Neurosci Res 1999; 55: 87-98.

145 Basura GJ, Nantwi KD, Goshgarian HG. Theophyllineinduced respiratory recovery following cervical spinal cord hemisection is augmented by serotonin 2 receptor stimulation. Brain Res 2002; 956: 1-13.

146 Benowitz LI, Goldberg DE, Irwin N. Inosine stimulates axon growth in vitro and in the adult CNS. Prog Brain Res 2002; 137: 389-399.

147 Culmsee C, Stumm RK, Schafer MK, Weihe E, Krieglstein J. Clenbuterol induces growth factor mRNA, activates astrocytes, and protects rat brain tissue against ischemic damage. Eur J Pharmacol 1999; 379: $33-45$.

148 Zeman RJ, Feng Y, Peng H, Etlinger JD. Clenbuterol, a beta(2)-adrenoceptor agonist, improves locomotor and histological outcomes after spinal cord contusion in rats. Exp Neural 1999; 159: 267-273.

149 Bareyre FM, Haudenschild B, Schwab ME. Long-lasting sprouting and gene expression changes induced by the monoclonal antibody $\mathrm{IN}-1$ in the adult spinal cord. J Neurosci 2002; 22: 7097-7110.

150 Dergham P, Ellezam B, Essagian C, Avedissian H, Lubell WD, McKerracher L. Rho signaling pathway targeted ;to promote spinal cord repair. J Neurosci 2002; 22: $6570-6577$.

151 Jones LL, Oudega M, Bunge MB, Tuszynski MH. Neurotrophic factors, cellular bridges and gene therapy for spinal cord injury. J Physiol (Lond) 2001; 533: 83-89; (Review) (48 refs).

152 Little JW, Burns SP, James JJ, Stiens SA. Neurologic recovery and neurologic decline after spinal cord injury. Phys Med Rehabil Clin N Am 2000; 11: 73-89.

153 Little JW, Harris RM, Smithson D. Motor recovery in the absence of segmental afferents: a case study of incomplete spinal cord injury. Paraplegia 1989; 27: 385-389.

154 Sumner BE. A quantitative analysis of the response of presynaptic boutons to postsynaptic motor neuron axotomy. Exp Neurol 1975; 46: 605-615.

155 Suresh BR, Muthusamy R, Namasivayam A. Behavioural assessment of functional recovery after spinal cord hemisection in the bonnet monkey (Macaca radiata). $J$ Neurol Sci 2000; 178: 136-152.

156 Fouad K, Metz GA, Merkler D, Dietz V, Schwab ME. Treadmill training in incomplete spinal cord injured rats. Behav Brain Res 2000; 115: 107-113. 